\title{
Gene Therapy Strategies Incorporating Large Transgenes
}

\author{
Jennifer Johnston, Christopher B. Doering and H. Trent Spencer \\ Emory University \\ U.S.A
}

\section{Introduction}

The application of nucleic acid therapeutics sometimes requires the transfer of relatively large transgenes. For example, treatment of diseases such as hemophilia A, sickle cell disease, muscular dystrophy, or cystic fibrosis requires the transfer of coding sequences or complex regulatory elements, which can exceed 4.5 kilobases $(\mathrm{kb})$. In general, transgenes are inserted into expression cassettes that can then be incorporated into either viral or nonviral vectors. The vector chosen depends not only on the therapeutic application but also on the size of the expression cassette. The size of the expression cassette depends on the size of the transgene and the requirement of specific regulatory elements necessary for appropriate transgene expression (for example, internal promoters, enhancers, insulators and other regulatory elements). Larger expression cassettes complicate gene therapy applications using viral vectors by (1) limiting the types of vectors available due to encapsidation limitations, (2) increasing the complexity of the transferred nucleic acid sequence, which, for example, can inadvertently introduce splice donor and acceptor sites, and (3) reducing the titer of viral vector that can be produced. Due to these hurdles, gene therapy strategies utilizing large expression cassettes are limited in vector design. One avenue of decreasing the size of transgenes is to genetically engineer minimal complementary DNA (cDNA) cassettes by eliminating regions that encode for non-functional aspects of the encoded protein. For example, the cDNA of human dystrophin, the missing functional gene in Duchenne's Muscular Dystrophy, is approximately $11 \mathrm{~kb}$. Due to its large size, a truncated functional version termed, mini-dystrophin, is utilized, thereby reducing the transgene size to $6 \mathrm{~kb}$. A similar strategy has also been evaluated for the cDNA encoding factor VIII (FVIII), mutations of which cause hemophilia A. The transgene size has been reduced by eliminating an entire domain, thus reducing the transgene size by $>2.5 \mathrm{~kb}$. A second strategy that has been evaluated involves dividing a larger transgene into smaller sub-transgenes that can then be incorporated into separate vectors to be delivered simultaneously. Nonviral gene-delivery systems, on the other hand, are not as constrained by the size of the expression cassette. Despite this advantage, nonviral vectors are currently not widely used because of inefficient gene transfer. However, rapid progress is being made with transposons circumventing limited transfer by capitalizing on their ability to integrate within the genome. For example, the Sleeping Beauty transposon has been used to insert a number of large expression cassettes into the human genome, including the $6.5 \mathrm{~kb} \beta$-globin expression cassette for the treatment of sickle cell disease. Therefore, these vectors hold much promise for gene therapy applications with large expression cassettes. 
The gene therapy field has a reasonable level of understanding regarding how to transfer and manage some of the larger therapeutic payloads, and excellent progress has been achieved for some diseases. The transfer of the cDNA sequence encoding FVIII incorporates many of the strategies used to transfer large transgene sequences. Therefore, this chapter will focus on the methods developed to transfer the FVIII transgene. But the strategies described in this chapter can be, and have been, used to transfer similarly large nucleic acid sequences. For example, as shown in Figure I, several parameters have been manipulated to achieve safe gene transfer and high level expression. This chapter will describe (1) the various gene transfer platforms, such as viral and nonviral gene transfer systems that are available and their likely applications to the transfer of large sequences, (2) various methods and techniques for modifying large transgene sequences for greater expression, and (3) the introduction of various accessory sequences, such as internal promoters in viral vectors and the WPRE sequence, both of which may aid in RNA expression and export from the nucleus. Because the transfer of the FVIII cDNA sequence has incorporated many of these parameters, it is an excellent model for developing strategies requiring the transfer of large nucleic acid sequences.

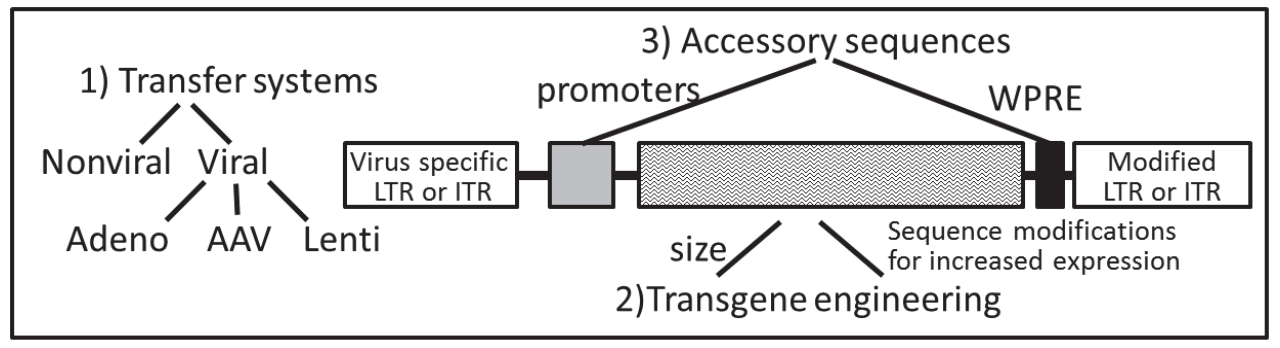

Fig. I. Schematic of a gene therapy expression cassette.

The various parameters noted above can potentially be modified in order to achieve efficient gene transfer and expression of large nucleic acid sequences.

\section{Hemophilia A as a disease model for the transfer of large transgenes}

Hemophilia $\mathrm{A}$ is an X-linked bleeding disorder attributed to the loss of a functionally secreted FVIII protein. Approximately 1 in every 5,000 males have hemophilia A, equating to approximately 400,000 people across the globe (Doering and Spencer, 2009). The current treatment consists of repetitive prophylactic administration of recombinant or plasma concentrated FVIII as a means of protein replacement. However, this treatment doesn't alleviate all the symptoms. Chronic joint pain can be experienced regardless of receiving optimal care. In addition, plasma concentrated FVIII historically has resulted in the transmission of blood borne pathogens (HIV, Hepatitis, etc.) to hemophilia patients and has thus, for the most part, been replaced with the administration of recombinant FVIII. Unfortunately, the recombinant form of FVIII is not available to a significant percentage (approximately 75\%) of the individuals affected by the disease (Doering and Spencer, 2009). This is mainly due to the expense of treating hemophilia A, which on average can be $\$ 250,000$ for recombinant FVIII product per year. Recombinant FVIII is costly because it is difficult to make resulting in periodic product shortages. It also has a low half-life in the 
circulation requiring repetitive multi-weekly administration to achieve prophylaxis. Further complicating the current therapy, some individuals who receive this treatment develop an immunogenic response in the form of neutralizing antibodies against the administered FVIII. These inhibitors make managing a bleeding episode in these individuals extremely complicated. Therefore, new therapeutic approaches are being developed to treat hemophilia A.

A monogenic disorder, such as hemophilia A, is a prime candidate for gene therapy for a number of reasons. First, the gene responsible for hemophilia A has been isolated and well characterized, which has led to useful preclinical mouse (Bi et al., 1995) and dog models (Kingdon \& Hassell, 1981) as well as a newly described sheep model (Porada et al., 2010). Second, the delivery of FVIII is not restricted to certain cell types. In fact, any tissue with exposure to the vasculature is an appropriate cellular target in that FVIII only needs to be secreted into the bloodstream for effectiveness. This makes a gene therapy approach relatively straightforward and achievable. Third, the therapeutic window is large. Only a moderate increase in FVIII ( $2-5 \%$ of normal equating to $2-5 \mathrm{ng} / \mathrm{ml}$ ) is required to be therapeutically effective while levels as high as $150 \%$ of normal have not been associated with adverse effects such as thrombosis (VandenDriessche et al., 2001). As a result, a number of viral and nonviral delivery strategies have been postulated.

\subsection{Previous clinical trials}

Three clinical trials to date have been conducted. Each utilized the human cDNA FVIII sequence, but all three differed in the manner whereby the nucleic acid sequence was incorporated into the patients' cells. The first trial by Roth et al. (2001) admitted six subjects with severe hemophilia A. Dermal fibroblasts were biopsied from each patient from the upper arm, expanded in tissue culture dishes in a laboratory incubator and electroporated (exposed to a voltage shock in order to perturb the cell membrane layer), resulting in the incorporation of the cDNA sequence into the fibroblast cells. After culturing, stably modified clones were selected and implanted into the omentum of each patient. Transient FVIII expression was observed within three of the patients for up to 6 months, with one patient expressing 4 percent of the normal amount of FVIII twelve weeks after implanting the genetically modified cells. However, the levels of FVIII diminished to less than $0.5 \%$ of normal a year later. The second trial included eleven subjects (Powell et al., 2003). Four doses $\left(2.8 \times 10^{7}, 9.2 \times 10^{7}, 2.2 \times 10^{8}\right.$, and $\left.4.4 \times 10^{8} \mathrm{TU} / \mathrm{kg}\right)$ of a retroviral vector based on the Moloney murine leukemia virus (MoMLV) were administered via peripheral vein injection over three consecutive days. No adverse effects were observed throughout the 53 week study. Yet once again only a transient expression of FVIII was achieved. Eight of the patients demonstrated greater than $1 \%$ of normal FVIII levels on two or more occasions yet these levels were not sustained throughout the study and could be associated with the administration of exogenous recombinant FVIII. The final trial was performed by GenStar Therapeutics. One patient was injected intravenously with an adenovirus, which contained the full-length human FVIII cDNA. The patient acquired an immune reaction to the virus and the trial was abruptly closed (Berlfein, 2003).

\subsection{The FVIII transgene}

The three clinical trials for hemophilia A used the human FVIII cDNA sequence instead of the wild-type FVIII gene sequence. This is due to the large size of the wild-type FVIII gene. 
In its entirety, the F8 gene is approximately 180 kilobases $(\mathrm{kb})$ long and is comprised of 26 exons. It is transcribed into a 9010 base pair (bp) transcript with a short $5^{\prime}$ untranslated region (150bp) and a large $3^{\prime}$ untranslated region (1806bp), and a $7056 \mathrm{bp}$ open reading frame the encodes the FVIII protein. The open reading frame of the FVIII transcript is translated into a protein containing a short 19 amino acid signal peptide, which is necessary for cellular excretion, and the 2332 amino acid protein with a distinct domain structure denoted A1-A2-B-A3-C1-C2. The B domain, comprising a total of 907 amino acids, is not found within the functional protein. Instead it contains sequence motifs recognized by both intracellular and extracellular proteases (Bowen, 2002). For example, FVIII is cleaved intracellularly after Golgi processing at two separate arginine residues within the B domain yielding a FVIII heterodimer composed of a heavy chain (A1 and A2 domains, as well as a shortened B domain) and a light chain (A3, C1 and C2 domains) held together by a calcium ion bridge. Further cleavage occurs extracellularly in which thrombin cleavage releases the remainder of the B domain resulting in FVIII activation (Lenting et al., 1998).

Large transgenes, such as the FVIII transgene, complicate gene therapy applications using viral vectors by (1) limiting the types of vectors available due to encapsidation limitations (see Table I) and (2) reducing the titer of viral vector that can be produced (Kumar et al., 2001; Radcliffe et al., 2008; Yacoub et al., 2007). The different human cDNA transgene lengths chosen for the clinical trials are a reflection of these limitations. The GenStar Therapeutics trial, unlike the other two trials, utilized an adenovirus which has fewer encapsidation constraints than other viral vectors available for gene transfer. As a result, it was the only trial to utilize the full-length cDNA $7 \mathrm{~kb}$ sequence. The Powell clinical trial, on the other hand utilized a retrovirus. Although retroviruses have the capability of encapsulating $7 \mathrm{~kb}$ of exogenous DNA, incorporating a $7 \mathrm{~kb}$ transgene into a retrovirus results in diminished viral titer making it difficult to achieve a high enough number of viral particles to be effective. Reducing the size of the insert, however, can increase viral titer (Yacoub et al., 2007). For this reason, many groups are using viral vectors and have reduced the size of the cDNA to approximately $4.5 \mathrm{~kb}$. This can be accomplished by removing sequence that encodes the $B$ domain, which has been found to be dispensable for the coagulation activity of FVIII (Toole et al., 1986).

\begin{tabular}{|l|l|c|c|c|}
\hline & Adenovirus & Adeno-associated virus & Lentivirus & Transposons \\
\hline Insert Size & $45 \mathrm{~kb}$ & $4.0 \mathrm{~kb}$ & $7 \mathrm{~kb}$ & $10 \mathrm{~kb}$ \\
\hline $\begin{array}{l}\text { Chromosomal } \\
\text { Integration }\end{array}$ & No & ${ }^{*}$ No & Yes & Yes \\
\hline $\begin{array}{l}\text { Route of gene } \\
\text { delivery }\end{array}$ & $\begin{array}{l}\text { Ex vivo } \\
\text { and in vivo }\end{array}$ & $\begin{array}{l}\text { Ex vivo } \\
\text { and in vivo }\end{array}$ & Ex vivo & $\begin{array}{l}\text { Ex vivo } \\
\text { and in vivo }\end{array}$ \\
\hline Titer & $10^{11}$ & $10^{12}$ & $10^{8}$ & N/A \\
\hline $\begin{array}{l}\text { Host immunological } \\
\text { response }\end{array}$ & Extensive & Moderate & Few & None \\
\hline $\begin{array}{l}\text { Pre-existing } \\
\text { immunity }\end{array}$ & Yes & Yes & Unlikely & No \\
\hline Safety concerns & $\begin{array}{l}\text { Inflammatory } \\
\text { Response, } \\
\text { Toxicity }\end{array}$ & $\begin{array}{l}\text { Inflammatory } \\
\text { Response, } \\
\text { Toxicity }\end{array}$ & $\begin{array}{l}\text { Risk of } \\
\text { Insertional } \\
\text { Mutagenesis }\end{array}$ & $\begin{array}{l}\text { Risk of } \\
\text { Insertional } \\
\text { Mutagenesis }\end{array}$ \\
\hline
\end{tabular}

* A low frequency (up to 10\%) of wild-type adeno-associated vectors has been found to integrate within chromosome 19 (Kotin et al., 1990).

Table I. Properties of major gene transfer methods used in gene therapy. 
As demonstrated above, the complications associated with the large FVIII transgene has led researchers to find innovative ways to apply gene therapy techniques to the transfer of the FVIII transgene. The following sections will discuss the methods that have been proposed for the pre-clinical testing of gene transfer technologies for FVIII. These methods will be outlined in reference to which vector is being used, since each vector is accompanied with its own set of limitations (Table 1). Both viral and nonviral vectors will be discussed, highlighting the strategies utilized to overcome the limitations experienced due to the use of a large transgene.

\section{Viral vectors}

Within the field of gene therapy, many viral vectors have been considered for the modification of cells, including both nonintegrating and integrating vectors. Nonintegrating vectors, such as the adenoviral and adeno-associated viral vectors, persist within cells extrachromosomally. As nonintegrating viruses, there is the risk that the vector genome will be lost, particularly if the modified cell divides. Yet, adenoviral vectors and adenoassociated viral vectors are appealing in that they efficiently transduce both dividing and non-dividing cells. If non-dividing cells are targeted then it is possible that long term expression can be achieved with these vectors. This quality allows these vectors to be able to target the most likely primary endogenous producers of FVIII, the terminally differentiated non-dividing hepatocytes.

Since adenoviral vectors are not constrained by insert size, they were among the first to be used as therapeutic gene transfer vectors within clinical trials. However as mentioned previously in reference to the GenStar FVIII clinical trial, systemic administration of adenoviral vectors resulted in acute toxicity (as evidenced by elevation of liver enzymes) as a result of the induction of pro-inflammatory cytokines and chemokines directed against the viral capsid proteins (Aruda, 2006; Brunetti-Pierri et al., 2004; Schnell et al., 2001; Muruve, et al., 1999; Yang et al., 1994). This toxicity can be circumvented if adenoviral vectors are administered neonatally, capitalizing on the immaturity of the immune system during early development. Therefore, adenoviral vectors are now being considered for use within neonates to induce FVIII tolerance. This was recently achieved within hemophilia A mice after intravenous injection of $5 \times 10^{12}$ vector particles $/ \mathrm{kg}$ administered at three days of age (Hu et al., 2011). FVIII levels peaked at $\sim 650 \%$ of normal on day six, but declined with animal growth as a result of episomal vector loss. Therefore, the single administration of adenoviral vectors within neonates was not able to achieve sustained therapeutic levels of FVIII. However, tolerance to the transgene and viral capsid proteins was achieved as noted by the lack of adverse effects after subsequent vector administration $(\mathrm{Hu}, 2011)$. It is worthwhile to note that this therapy could also be beneficial, in the absence of subsequent vector administration, to prevent the development of inhibitors to FVIII which currently complicates protein replacement therapy. In the context of gene therapy for hemophilia A, adenoviral vectors are only being considered for the induction of FVIII tolerance within neonates due to the extensive inflammatory response observed after presentation of the vector to the systemic circulation. This is unfortunate since the vector can withstand the large size of the FVIII transgene as well as any number of regulatory elements used within the field for expression enhancement or safety. Adeno-associated viral vectors, on the other hand, are being extensively evaluated for use within gene therapy. 


\subsection{Gene transfer of FVIII with adeno-associated viral vectors}

The adeno-associated viruses are relatively small viruses, composed of a linear singlestranded DNA genome of approximately $4.6 \mathrm{~kb}$. As of 2009, twelve different serotypes have been isolated from both human and non-human primates (a number which is expected to increase), all of which vary in transduction efficiency and tissue tropism (Youjin and Jun, 2009). Serotype 2 (AAV-2) was the first adeno-associated virus to be sequenced and cloned, and was therefore the first serotype to be used within gene transfer studies (Hermonat and Muzyczka, 1984; Laughlin et al., 1983; Samulski et al, 1982). Wild-type AAV-2 was found to encode two large open reading frames, composed of the replication (Rep78, Rep68, Rep52, and Rep40) and capsid genes (VP1, VP2, and VP3). To accommodate transgenes, these genes were removed leaving behind the inverted terminal repeats required for replication and packaging into a viron (Youjin and Jun, 2009). AAV-2 and other AAV serotypes have the ability to efficiently transduce both non-dividing and dividing cells (Hallek et al., 1998). This quality makes modifying hepatocytes in vivo possible, making them a potentially ideal vector for FVIII delivery. In this aspect, hepatocytes have been modified by a number of adeno-associated viral serotypes. For example, AAV-2, after intraportal administration, transferred a canine B domain deleted version of FVIII to liver cells, which resulted in partial phenotypic correction of hemophilia A mice. Although FVIII activity initially peaked to $8 \%$ of normal, expression was not sustained, declining to $2 \%$ nine months after injection (Sarkar et al., 2003). These findings, although confirmed independently by Jiang et al. (2003), are contradictory to similar preclinical and clinical studies for hemophilia B in which therapeutically effective levels of FIX are sustained over time (Manno et al., 2005 and Schuettrumpt et al., 2005). This is because FIX is a significantly smaller transgene than FVIII with a cDNA of $2.8 \mathrm{~kb}$. This smaller sequence allows for the inclusion of larger regulatory elements (such as liver specific promoters and enhancers) within the adeno-associated viral vector that are not able to be incorporated after the inclusion of the FVIII cDNA sequence. Within the Jiang (2003) and Sarkar (2003) reports, a minipromoter was all that could be incorporated into the AAV-2 vector to promote FVIII expression. Therefore, it was concluded that regulatory elements, that were unable to be included in the AAV-2 vector (due to insert size restraints associated with adeno-associated viral vectors), were required to enhance FVIII expression. A follow up study evaluated additional adeno-associated viral serotypes (AAV-5, AAV-7, and AAV-8) to determine if other serotypes were more efficient at transducing hepatocytes than AAV-2. For the inefficient transfer of large transgenes, it was hypothesized that by increasing hepatocyte transduction, limited expression could be overcome without the inclusion of regulatory expression-enhacement elements. They found that AAV-8 was superior to other serotypes regardless of route of administration (intraportally or intravenously) producing near normal physiological levels of FVIII (0.58 \pm $0.2 \mathrm{IU} / \mathrm{mL}$ ) six months post administration at a vector dose of $1 \times 10^{11}$ vector copies / mouse (Sarkar et al., 2004). A similar comparison was performed by Jiang et al. (2006), comparing four serotypes (AAV-2, AAV-5, AAV-6, and AAV-8), within both mice and dogs. Within mice, transduction efficiency was found to be least with AAV-5 and greatest with AAV-8. However for dogs, no substantial difference was observed among the serotypes. Remarkably though, FVIII expression was sustained in some dogs ( 2 to $5 \%$ of normal) for up to three years, resulting in decreased occurrences of spontaneous bleeds (Jiang et al., 2006). This was a significant contribution to the field being the first multiyear report of therapeutic efficacy and safety within dogs. Albeit, high vector doses of $6 \times 10^{12}$ and $2.7 \times 10^{13}$ vector genomes/kilogram were required to yield these subtherapeutic levels of FVIII. 
Despite the phenotypic improvements noted above, the inclusion of regulatory elements to the vector for enhancing the expression of FVIII would have been the simplest way to address the limited hepatocyte transduction that was seen with AAV-2. Yet since adenoassociated viral vectors are restricted in their genetic carrying capacity, other avenues had to be evaluated to overcome this limitation. Some reports show packaging of genomes greater than 5kb within adeno-associated vectors (Alloca et al., 2008 and Grieger and Samulski, 2005). For example, it is reported that an AAV-8 viral vector was produced containing the $B$ domain deleted human FVIII transgene as well as a full length promoter and enhancer, totaling $5.75 \mathrm{~kb}(\mathrm{Lu}, 2008)$. However, extensive examination within this report as well as by $\mathrm{Wu}(2010)$ clearly showed that inserts ranging from $4.7 \mathrm{~kb}$ to $8.7 \mathrm{~kb}$ result in heterogenous virons of varying genome lengths, typically containing truncations at the $5^{\prime}$ end. Thus, increasing the size of the adeno-associated vector genome leads to the formation of defective viral particles encapsulating incomplete transgene sequences (Dong et al., 1996).

For these reasons, several groups are attempting to overcome the packaging limitation with the use of two different vectors, one for the heavy chain and one for the light chain of FVIII. This strategy resulted from the demonstration of secretable biologically active FVIII following co-transfection within Chinese hamster ovary cells of two plasmids separating the heavy and light chains (Burke et al, 1986 and Yonemura et al., 1993). Within these cells the two polypeptide chains were able to reconstitute a functional FVIII heterodimer that was secreted into the cellular media. Although this strategy may be unique to hemophilia A gene therapy applications due to the structural properties of the protein, similar strategies could be implemented in other large transgenes. This strategy was first performed in C57BL/ 6 mice by intraportal administration (Burton et al., 1999). These mice were chosen since this strain does not elicit an immune response to the FVIII transgene, allowing expression to be measured without any contraindications. As a result, greater than physiological levels of FVIII were produced. These results were then extended into the hemophilia A mouse model where therapeutic levels of FVIII were achieved in a dosedependent manner. High levels of transduction were noted with twelve percent of hepatocytes being modified with both vectors. Complicating the issue, a chain imbalance was noted with a 25 to 100 fold excess of light chain. This was found to be due to inefficient translational or posttranslational processing that could not be circumvented by changing the administration ratio of heavy to light chain vectors (Scallan et al., 2003). When extended to the hemophilia A dog model, only partial phenotypic correction was achieved, irrespective of adeno-associated serotype used. Although only modest levels of FVIII were observed in the dogs (ranging from 1 to $8 \%$ of normal), these levels were found to be sustained for at least two years (Sarkar et al., 2006).

Another strategy used to overcome the inability of adeno-associated vectors to deliver large genes is trans-splicing. Trans-splicing attempts to repair the truncated FVIII mRNA in vivo by delivering the remaining downstream pre-mRNA. Within this strategy, a pre-transsplicing molecule is delivered by an adeno-associated vector in which complementary mRNA sequences are located at the $5^{\prime}$ end of the molecule designed to be spliced with the preexisting truncated FVIII mRNA due to a strong splice site at the $3^{\prime}$ end. In this way, a shortened version of the transgene can be delivered in vivo to restore the disease phenotype. This method was performed in hemophilia A mice (Chao et al., 2003). Hemophilia A mice were created by inserting a neomycin resistance gene into the sixteenth exon of FVIII (Bi et al., 1995). As a result truncated FVIII mRNA is still expressed within these mice. By delivering a pre-trans-splicing molecule containing complementary sequence to intron 15 , a 
functional FVIII pre-mRNA was spliced together in vivo resulting in phenotypic correction within eight of the ten injected mice.

Despite these efforts the fact remains that nonintegrating adeno-associated viral vectors are unable to stably transduce cells. Therefore, many groups are focusing on the use of integrating viral vectors such as gamma-retroviral and lentiviral vectors. Lentiviral vectors, such as HIV and SIV, have been analyzed for their use within gene therapy since 1996 in which Naldini and colleagues revealed the ability of these vectors to overcome the need for cell division during transduction. Being able to transduce both dividing and non-dividing cells gives lentiviral vectors the same advantage as adeno-associated viral vectors. For this reason, lentiviral vectors are likely to make up a second generation of therapeutic vectors to be tested in clinical trials.

\subsection{Gene transfer of FVIII with lentiviral vectors}

Stable integration of a transgene can be achieved with integrating viruses, such as gammaretroviral and lentiviral vectors. However, genomic integration of a viral vector has concerned the gene therapy community because of the possibility of cellular transformation due to integration of the transgene near an oncogene. This process has been termed insertional mutagenesis, and can cause misregulation of oncogene expression, which could subsequently lead to malignancy. Historically, insertional mutagenesis has been debatable due to the lack of data confirming its occurrence. However, recent data has confirmed the possibility of insertional mutagenesis due to retroviruses. First, retroviruses have been found to insert into the genome near promoters of transcriptionally active genes, setting the stage for the disrupted regulation of downstream genes (Wu et al., 2003). Second, direct proof of insertional mutagenesis has been documented in human gene therapy clinical trials for the treatment of severe combined immune deficiency syndrome that used gamma-based retroviruses (Hacein-Bey-Abina et al., 2003). In the initial clinical trials, of the 20 treated children, 5 have developed a T-cell leukemia-like disorder. The cause of the leukemia has been found to be due to integration of the gamma-retrovirus upstream of the oncogene, LMO2. Integration at this site disrupted the regulation of the oncongene increasing the expression of LMO2. The confirmation of insertional mutagenesis with gamma-retroviral vectors halted their use for clinical development for hemophilia. However, no direct evidence for insertional mutagenesis has been documented for recombinant lentiviral-based retroviruses. Instead, lentiviral vectors have been promising vectors for the delivery of the FVIII transgene because, like adeno-associated viral vectors, they are able to transduce both dividing and non-dividing cells, (Naldini et al., 1996) but unlike adeno-associated viral vectors are not as constrained by the size of the transgene. For these reasons, lentiviral vectors are ideal for gene therapy applications aimed for the treatment of hemophilia A.

The first lentiviral vectors contained all of the viral genes except for the envelope gene (Naldini et al., 1996). Since then numerous safety measures have been taken to ensure the safety of the virus in the unlikely event of generating a replication competent lentivirus. Second generation HIV-based vectors removed 5 of the 9 viral genes, eliminating accessory genes (Quinonez \& Sutton 2002). As an added precaution second generation lentiviral vectors have been designed as replication incompetent self-inactivating (SIN) vectors. This has been accomplished by removing $133 \mathrm{bps}$ from the $3^{\prime}$ long terminal repeat (LTR). LTRs flank viral DNA at both the $3^{\prime}$ and $5^{\prime}$ ends and are involved in the integration process (for further discussion refer to Sinn et al., 2005). During the process of integration, the $3^{\prime}$ LTR is copied and becomes the 5'LTR in the integrated sequence, which inactivates the integrated 
5'LTR. Further safety measures resulted in the third generation lentiviral vectors, in which 2 more viral genes (the tat and the rev genes) were eliminated. To date these third generation lentiviral vectors have been used for gene therapy applications without any adverse complications (Cartier et al., 2010).

Lentiviral vectors have a carrying capacity of approximately $7 \mathrm{~kb}$ exogenous DNA. Although still constrained by encapsidation limitations, lentiviruses can be used to shuttle a number of transgenes that are restricted within the adeno-associated viral vector. However, as the insert size increases the viral particles produced (as measured by viral titer) can decrease (Yacoub et al., 2007). This phenomenon has been observed by several laboratories that use the $4.5 \mathrm{~kb}$ B domain deleted FVIII transgene. Because of this limitation, focus has been on reducing the insert size within the lentiviral vector. One component of the viral vector, which can be considered to be removed for this purpose, is the woodchuck posttranscriptional regulatory (WPRE) sequence ( $\sim 600 \mathrm{bp})$.

Zufferey et al. (1999) incorporated a WPRE sequence at the 3' end of the transgene and demonstrated a 2- to 5- fold increase in expression. The enhancement in expression appears to be due to increased export of unspliced mRNA (Zuffery et al., 1999). Viral vectors used for the purpose of gene therapy utilize cDNA sequences, which are not spliced due to vector size constraints and therefore experience limited export of the mRNA. This limited export of unspliced transgene mRNA compounds the low level expression obstacle experienced historically. Thus, the inclusion of either splice donor and acceptor sites or a WPRE sequence appears to be ideal. As a result, the WPRE has routinely been incorporated into viral vectors. However, a recent report showed that the function of WPRE as a transgene expression enhancer may not be as advantageous as previously determined. The enhancement of transgene expression due to a WPRE sequence was found to be dependent on the promoter and cell line used. In general, the WPRE sequence enhances transgene expression, but in some instances no increase and even a decrease in transgene expression is observed. It was concluded that the function of the WPRE is more complex than originally assumed and should be evaluated in conjunction with every transgene (Klein et al., 2006). For this reason, the WPRE was evaluated in the context of an optimized high-expressing FVIII transgene and found to be negligible in regards to transgene expression as assessed by both transcript number and FVIII activity (Johnston et al., 2010). The effects were also negligible in regards to viral transduction. For these reasons, the WPRE can be considered for removal from some lentiviral backbones in order to reduce the insert size.

To further overcome issues of FVIII expression several bioengineered FVIII constructs have been proposed, many of which target the efficient transport of FVIII from the endoplasmic reticulum to the golgi (Dorner et al., 1987). For example, removal of the B domain, besides shortening transgene length, was also found to be beneficial by increasing mRNA production 20-fold (Meulien et al., 1988). However, efficient secretion of FVIII requires Nlinked glycosyl residues found within the B domain. Therefore, retaining these sites within a truncated B domain may be a preferred shortened FVIII construct (Miao et al., 2004). In addition to the above engineering schemes, amino acid substitutions within the A1 domain were incorporated in order to diminish binding to an ER resident protein chaperone, which resulted in enhanced FVIII production (Marquette et al., 1995 and Swaroop et al., 1997). A B domain deleted porcine FVIII transgene was also evaluated revealing a 10 - 14 fold increase in expression compared to a human FVIII transgene (Doering et al., 2002). Its subsequent transfer within hemophilia A mice resulted in high-level FVIII expression that could be sustained even after low-toxicity pretransplantation conditioning (Ide et al., 2007). Together, 
these studies demonstrated the ability of a high-expressing porcine FVIII construct to function in vivo. A comparison of these transgenes revealed the superiority of the porcine Bdomain-deleted FVIII with a 36 to 225-fold increase in FVIII expression (Dooriss et al., 2009). These findings suggested that the current low-level expression obstacle could be eliminated if the sequences that are responsible for the enhanced secretion of porcine FVIII were identified. To accomplish this, human/porcine FVIII chimeras were constructed that revealed sequences within the A1 and A3 domains to be responsible for enhanced secretion of porcine FVIII (Gangadharan et al., 2006). The result was a hybrid human/porcine construct comprising 90\% human FVIII, designated HPFVIII, which has been shown to maintain the high-expression characteristics of the porcine sequence. This optimized HPFVIII transgene has recently been used to treat hemophilia A mice, which resulted in therapeutic levels of FVIII being observed after modifying hematopoietic stem cells (HSC) ex vivo with lentiviral vector (Doering et al., 2009). A codon optimized FVIII cDNA also has been reported and shown to enhance expression after in vivo administration to neonatal hemophilia A mice (Ward et al., 2011).

Reduction in transgene titers due to issues associated with transgene size can be overcome by targeting various cell populations ex vivo then expanding the genetically modified cells. Therefore, despite diminished titer production, preclinical progress has been made with lentiviral vectors encoding the $4.5 \mathrm{~kb}$ B domain deleted FVIII transgene. And, by targeting specific cells, viral transduction can be optimized and enhanced, which further overcomes the reduction in titer due to transgene size. In addition, ex vivo modification of cells is considered safer than the in vivo delivery of recombinant virus since it eliminates the possible transmission to germline cells, as well as avoiding any systemic toxicity that can result due to direct presentation of the vector particle (Van Damme et al., 2004). Ex vivo modification also eliminates the issue of modifying antigen-presenting cells, possibly eliminating the development of an immune response to the transgene.

Ex vivo gene therapy for hemophilia A has been analyzed within a broad range of cell types (Viiala et al., 2009). Cellular alternatives considered include embryonic stem (ES) cells, bone marrow derived mesenchymal cells, blood outgrowth endothelial cells (BOECs), and HSCs (as discussed previously). Stem cells are a reasonable alternative in that they have unlimited replicative potential and contain the ability to differentiate into a wide range of cells. However, the initial use of stem cells within the field of gene therapy resulted in low expression levels. This was thought to either be due to gene inactivation as a result of extensive differentiation (McIvor, 1987) or an inability to effectively transduce stem cells. Regardless, promising results were published utilizing an inducible system for FVIII within ES cells. However, both ethical and safety concerns have inhibited the continuation of these studies (Kasuda et al., 2008). This is due to the controversy surrounding the generation of ES cells from human embryos, as well as the formation of teratomas which arose from undifferentiated ES cells used for insulin production (Fujikawa et al., 2005). Fortunately, induced pluripotent stem cells (iPS) appear to be comparable to ES cells and have thus been considered to treat monogenic disorders in order to alleviate the ethical concerns surrounding stem cell usage. iPS cells are derived from adult somatic cells which have been reprogrammed to have stem cell characteristics. Significant progress has been made utilizing iPS cell-based therapy for murine hemophilia A (Xu et al., 2009). However, these methods are fairly new and still do not address the potential formation of teratomas. Therefore, many obstacles need to be addressed before this therapy can reach the clinics (for further discussion refer to Liras, 2011). Another cell type, bone marrow derived mesenchymal cells, 
initially yielded therapeutic levels of FVIII from transduced human mesenchymal cells within immunodeficient mice. Yet FVIII plasma levels deteriorated gradually in spite of the persistence of gene modified cells, suggesting transcriptional repression within this cell type (Van Damme et al., 2004). Human BOECs can be isolated from the peripheral blood of healthy donors and were considered as FVIII gene transfer targets because they express von Willebrand factor (vWF). vWF binds with high affinity to FVIII in the circulation and protects FVIII from degradation and uptake by antigen presenting cells (possibly eliminating the development of an immune response to the transgene) (Dasgupta et al., 2007). Therefore, it was hypothesized that modifying these cells to also express FVIII would result in the secretion of FVIII complexed to vWF, which would result in an increased halflife of FVIII, secreted at sites of injury. After transduction, BOECs expressed high levels of FVIII measured at $1.6 \mathrm{pmol} /$ million cells/24hrs, which lasted for over thirty days in culture. FVIII was found to be stored within the same vesicles as VWF within the BOECs but was not found to be released upon agonist stimulation, unlike vWF. Instead, FVIII appeared to be released in a constitutive manner (van den Biggelaar et al., 2009). When BOECs were implanted into immunocompetent hemophilic mice, FVIII levels were within the therapeutic range for a total of 27 weeks. Afterwards, the levels declined to baseline due to loss of the implanted BOECs (Matsui, et al., 2007). Although a benefit for FVIII secretion with vWF was not directly tested, the proof of concept was shown for the expression of FVIII from BOECs. Another cell target, which has been considered, is skeletal muscle cells. Skeletal muscles cells are an ideal target for in vivo gene transfer in that skeletal muscle cells are terminally differentiated and provide a consistent source of FVIII persisting throughout the lifetime of an individual. For these reasons, Jeon et al. (2010) injected $10^{7}$ lentiviral particles intramuscularly into the thigh of rats and found plasma FVIII levels to increase slightly above that of control mice for up to 4 weeks before deteriorating. Despite the need for follow up studies in order to achieve therapeutic levels of FVIII with this strategy, the results suggested that the in vivo administration of a lentivirus targeted at skeletal muscle cells may be an effective strategy for the treatment of hemophilia A. Most in vivo strategies, however, are aimed at targeting hepatocytes, the endogenous producer of FVIII. Lentivirus is administered via either the portal vein or intravenously. Unfortunately this strategy in the case of FVIII (a protein with extensive immunogenicity properties), results in the presentation of anti-FVIII antibodies due to the possible transduction of antigen presenting cells. To overcome this, a miRNA sequence was incorporated downstream of the WPRE sequence which would prevent expression within hematopoietic cells (including cells which make up the immune system). This method was found to be very effective in eliminating a FIX immune response (Brown et al., 2007), but alone was unable to do so with FVIII. Instead the FVIII-miRNA lentivirus had to be pseudotyped with the baculovirus envelope glycoprotein GP64, which has been shown to restrict transduction away from hematopoietic stem cells (Schauber et al., 2004). Combined, the miRNA incorporation and the GP64 pseudotyping were able to restrict FVIII expression to the liver, eliminating the presence of inhibitors, while resulting in about $9 \%$ of normal levels of FVIII $(0.1 \mathrm{U} / \mathrm{mL})$, which was sustained in mice for a total of 60 weeks (Matsui, 2010). This study was significant in that it modified the current in vivo lentiviral gene transfer of FVIII making it safer by restricting expression within the liver.

In contrast to focusing on transferring the missing or malfunctioning gene, constructs that encode proteins that can bypass the missing protein can be used to overcome the difficulties associated with the size of the transgene. In the case of hemophilia A, a smaller gene such as FVII can be used to bypass the need for FVIII. FVII is an extrinsic pathway coagulation 
factor that along with thromboplastin initiates the blood coagulation proteolytic cleavage cascade and has been shown in a recombinant form to be an alternative treatment for hemophilia A (Jurlander et al., 2001). For these reasons, Ohmori et al. (2008) transduced HSCs ex vivo with a simian immunodeficiency virus (SIV)-based lentiviral vector encoding an activated form of FVII expressed from a platelet specific promoter (the GPIba promoter). As a result, FVII was found to localize to the cell surface following platelet activation within transplanted FVIII-deficient mice. Due to species-specific interactions, the murine TF was unable to interact with the human form of FVII resulting in unimproved hemophilia conditions within the FVIII-deficient mice. However, when a murine FVII was incorporated into the SIV-based lentiviral vector, the clot time and rate of clot formation were significantly reduced, decreasing the mortality rate after tail clipping (Ohmori et al., 2008). In addition, FVII was recently incorporated into an adeno-associated vector (AAV-8) being able to overcome the encapsidation limitations of the vector due to the shorter size of FVII. Yet it was shown that within hemophilic dogs, large doses of vector were required to be efficacious (Margaritis et al., 2009). Therefore, a bioengineered FVII variant with enhanced intrinsic activity was recently utilized in order to reduce the dose of in vivo administered vector. However, adverse thrombotic effects were observed in treated mice, which limits enthusiasm for this therapy. (Margaritis et al., 2011).

\section{Nonviral vectors}

Unlike viral vectors, nonviral vectors themselves do not risk evoking an immunological response, are less expensive to produce, and are less limited by the size of the transgene. As a result, naked DNA gene transfer was among the first methods to be utilized in a clinical trial for hemophilia A (Roth et al., 2001). However, this strategy results in transient gene expression because of limited uptake by target cells and further limited integration into the genome of these cells (a process that unless further manipulated occurs only randomly through nonhomologous recombination) (Essner et al., 2005). This issue can be overcome by promoting stable integration into the cell's genome with the use of a transposable element. Transposable elements, although mostly inactive, are found to be littered throughout the human genome (Deininger and Batzer, 2002). In an active form, transposable elements (transposons) have the ability to jump from one location in the genome to another by a "cutand paste" method through the enzyme transposase, which is encoded within the element. In order for a transposon to be utilized as a gene transfer vehicle, two components must be delivered to the target cell, (1) the transgene flanked by inverted repeat/direct repeat elements that are recognized for integration, and (2) a transposase which can be encoded within the same plasmid or within a second plasmid. These plasmids can be taken up into cells after being complexed to a cationic polymer such as polyethylenimine (PEI).

Although transposons can carry an expansive amount of DNA, transposons are still somewhat limited by insert size. Integration efficiency has been shown to decrease with the size of the transgene (Essner et al., 2005). This is due to both the difficulties in delivering plasmids containing larger inserts as well as the limitations of the transposase. For example, the transposase enzyme associated with the Sleeping Beauty transposon, the most notable nonviral gene-delivery system currently used, is only able to transpose up to $10 \mathrm{~kb}$.

\subsection{Gene transfer of FVIII with a transposon}

Transposons have been utilized as a nonviral vector for gene therapy of hemophilia A by a number of groups. The Sleeping Beauty transposon system was engineered from an inactive 
Tc1-like transposable element found within fish (Ivics et al., 1997). It has since been used to insert a number of large expression cassettes into the human genome, including the $6.5 \mathrm{~kb}$ aglobin expression cassette for the treatment of sickle cell disease ( $\mathrm{Zhu}$ et. al, 2007). For hemophilia A, the Sleeping Beauty transposon/transposase system was utilized by Liu et al. (2006) to express the human B domain deleted FVIII cDNA within endothelial cells. FVIII levels remained at $\sim 12 \%$ of normal after intravenous plasmid injection through the temporal vein of neonatal hemophilia A mice. However, the presence of inhibitors to FVIII resulted in only partial phenotypic correction (Liu et al., 2006). In order to circumvent the presence of inhibitors, the Largaespada group tolerized neonatal, one day old, hemophilia A mice to FVIII with a facial vein injection of $0.1 \mathrm{U} / \mathrm{g}$ of recombinant human FVIII. Eight to twelve weeks later, two high pressure tail vein injections of a Sleeping Beauty transposon were administered. As a result, $16 \%$ of normal FVIII levels were seen within these mice at eightyfour days after plasmid injection, which was found to be sustained for 6 months. No inhibitors were detected and an improvement in clotting function was noted (Ohlfest et al., 2005).

The high-pressure method of delivery is accomplished by injecting a high volume into the systemic circulation (termed hydrodynamic injections). Within the mouse, this results in DNA uptake followed by expression within the liver. Designed to overcome the difficulties of delivering DNA to the nucleus of a cell, high-volume high-pressure injection is not yet applicable for people (Essner et al., 2005). Therefore, other methods of transposon delivery are being explored. One method that is being studied is the cell specific delivery of a transposon by encapsulation within a nanocapsule. A recent report by Kren et al. (2009) utilized a novel dispersion atomization technique to encapsulate the Sleeping Beauty transposon system. The engineered nanocapsule was targeted to liver sinusoidal endothelial cells (LSECs) by coating the capsule with an endogenous ligand for the hyaluronan receptor found on LSECs. Inside the nanocapsule a single plasmid was encapsulated containing both a cis-acting transposase as well as the B domain deleted canine FVIII transgene. Eight-week old hemophilia A mice were injected with $25 \mu \mathrm{g}$ of nanocapsule via tail vein injection. FVIII levels were measurable for a total of 11 months.

The size limitations of transposons have recently been expanded. Recently, a number of improvements have been made resulting in a hyperactive transposase, which appears to be able to improve transpositional efficiency to transgenes greater than $10 \mathrm{~kb}$ (Zayed et al., 2004). These improvements will be useful for the transfer of large transgenes and expression cassettes within gene therapy.

\section{Conclusion}

Gene delivery systems are available for the routine delivery of nucleic acid sequences below approximately $3 \mathrm{~kb}$. As the transgene size increases beyond this, the complexity of transferring the larger sequences increases as well. Many systems have been tested for transferring large transgene sequences and some have shown reasonable promise. In general, viral vectors efficiently transfer these larger sequences, but several hurdles hamper gene transfer, namely: (1) limitations in the size of genetic material that can be packaged in a viral vector, (2) the inadvertent introduction of splice donor and acceptor sites, and (3) reduction of viral titer. Therefore, although efficient gene transfer systems are available, and clinical trials have confirmed the usefulness of some systems, there is still a need for improved gene transfer systems for large payloads. Even though optimal systems are not 
available, several strategies can be used to transfer large nucleic acid sequences. These strategies revolve around manipulating the various components of the expression cassette, specifically (1) introducing the sequence into multiple viral or nonviral gene transfer system to determine the best for the specific transgene (2) modifying the transgene sequence, for example by deleting coding sequences that may not be important to the function of the expressed protein, and (3) removing various accessory sequences that may not be necessary, or incorporating accessory sequences with optimal expression properties, such as stronger promoter elements. The transfer of FVIII is an excellent example of how some of these limitations were overcome. The transgene that encodes FVIII is very large $(7 \mathrm{~kb})$. Within the context of expressing FVIII for the treatment of hemophilia A, both viral and nonviral vectors have been tested. Viral vectors were first used to provide proof-of-principle that hemophilia A could be treated by gene therapy (VandenDriessche et al., 1999). However, the efficiency of FVIII gene transfer has hampered the progress of developing a gene therapy treatment for hemophilia A. Since then, the FVIII transgene has been truncated from $7 \mathrm{~kb}$ to $4.5 \mathrm{~kb}$ by removing the $\mathrm{B}$ domain, a non-functional region of the protein. A number of groups have focused on shortening FVIII even further by dividing FVIII into two smaller sub-transgenes, one encoding the heavy chain and another encoding the light chain. Besides focusing on the FVIII transgene itself, other components of the expression cassette have also been evaluated, such as removal of the WPRE sequence and testing of various promoters. Despite these innovative methods, viral vector design is limited, prohibiting the addition of other regulatory or safety sequences. Nonviral vector systems, on the other hand, are not as constrained by the size of the expression cassette. However, these vectors have been historically associated with inefficient and unstable gene transfer. The Sleeping Beauty transposon may be able to circumvent this disadvantage by stably integrating the transgene into the target cell's genome. Overall, tremendous progress has been made to overcome the limitations associated with large expression cassettes. We now have a reasonable level of understanding, within the gene therapy field, of the limitations of the various gene transfer systems. The ability to transfer larger and more complex genetic expression cassettes will allow for more sophisticated approaches for targeting and treating diseases that currently are not being addressed because of transfer limitations.

\section{References}

Allocca, M., Doria, M., Petrillo, M, Colella, P., Garcia-Hoyos, M., Gibbs, D., Kim, S.R., Maguire, A., Rex, T.S., Di Vicino, U., Cutillo, L., Sparrow, J.R., Williams, D.S., Bennett, J., and Auricchio, A. (2008) Serotype-dependent packaging of large genes in adeno-associated viral vectors results in effective gene delivery in mice. Journal of Clinical Investigation, Vol. 118, No. 5, (May), pp. 1955-1964, ISSN 0021-9738

Aruda, VR. (2006) Toward gene therapy for hemophilia A with novel adenoviral vectors: success and limitations in canine models. Journal of Thrombosis and Haemostasis, Vol. 4, No. 6, (June), pp. 1215-1217, ISSN 1538-7933

Berlfein, J. (2003) Clinical trial update. Hemaware, Vol. 8, No. 5, (September), pp. 52-53

Bi, L., Lawler, A.M., Antonarakis, S.E., High, K.A., Gearhart, J.D., and Kazazian, H.H. (1995) Targeted disruption of the mouse factor VIII gene produces a model of haemophilia A. Nature Genetics, Vol. 10, No. 1, (May), pp. 119-121, ISSN 1061-4036

Brown, B.D., and Cantore, A., Annoni, A., Sergi, L.S., Lombardo, A., Della Valle, P., D'Angelo, A., and Naldini, L. (2007) A microRNA-regulated lentiviral vector 
mediates stable correction of hemophilia B mice. Blood, Vol. 110, No. 13, (December), pp. 4144-4152, ISSN 0006-4971

Brunetti-Pierri, N., Palmer, D.J., Beaudet, A.L., Carey, K.D., Finegold, M., and Ng, P. (2004) Acute toxicity after high-dose systemic injection of helper-dependent adenoviral vectors into nonhuman primates. Human Gene Therapy, Vol. 15, No. 1, (January), pp. 35-46, ISSN 1043-0342

Burke, R.L., Pachl, C., Quiroga, M., Rosenberg, S., Haigwood, N., Nordfang, O., and Ezban, M. (1986) The functional domains of coagulation factor VIII:C. Journal of Biological Chemistry, Vol. 261, No. 27, (September), pp. 12574-8, ISSN 0021-9258

Burton, M., Nakai, H., Colosi, P., Cunningham, J., Mitchell, R., and Couto, L. (1999) Coexpression of factor VIII heavy and light chain adeno-associated viral vectors produces biologically active protein. Proceedings of the National Academy of Sciences, Vol. 96, No. 22, (October), pp. 12725-12730, ISSN 0027-8424

Bowen, D.J. (2002) Haemophilia A and haemophilia B: molecular insights. Molecular Pathology, Vol. 55, No. 1, (February), pp. 1-18, ISSN 1472-4154

Cartier, N., Hacein-Bey-Abina, S., Von Kalle, C., Bougnères, P., Fischer, A., CavazzanaCalvo, M., and Aubourg, P. (2010) Gene therapy of x-linked adrenoleukodystrophy using hematopoietic stem cells and a lentiviral vector. Bull Acad Natl Med, Vol. 194, No. 2, (February), pp. 255-64, ISSN 0001-4079

Chao, H., Mansfield, S.G., Bartel, R.C., hiriyanna, S., Mitchell, L.G., Garcia-Blanco, M.A., and Walsh, C.E. (2003) Phenotype correction of hemophilia A mice by spliceosomemediated RNA trans-splicing. Nature Medicine, Vol. 9, No. 8, (August), pp. 10151019, ISSN 1078-8956

Dasgupta, S., Repesse, Y., Bayry, J., Navarrete, A.M., Wootla, B., Delignat, S., Irinopoulou, T., Kamaté, C., Saint-Remy, J.M., Jacquemin, M., Lenting, P.J., Borel-Derlon, A., Kaveri, S.V., and Lacroix-Desmazes, S. (2007) VWF protects FVIII fron endocytosis by dendritic cells and subsequent presentation to immune effectors. Blood, Vol. 109, No.2 , (January), pp. 610-612, ISSN 0006-4971

Deininger, P. and Batzer, M. (2002) Mammalian Retroelements. Genome Research, Vol. 12, No. 10, (October), pp. 1455-1465, ISSN 1088-9051

Doering, C., Parker, E., Healey, J., Craddock, H., Barrow, R., and Lollar, P. (2002) Expression and characterization of recombinant murine FVIII. Journal of Thrombosis and Haemostasis, Vol. 88, No. 3, (September), pp. 450-458, ISSN 1538-7933

Doering, C. and Spencer, T. (2009) Advancements in gene-transfer based therapy for hemophilia A. Expert Review of Hematology, Vol. 2, No. 6, (December), pp. 673-683, ISSN 1747-4086.

Doering, C., Denning, G., Doriss, K., Gangadharan, B., Johnston, J., Kerstann, K., McCarty, D., and Spencer, T. (2009) Directed Engineering of a High-expression chimeric transgene as a strategy for gene therapy of hemophilia A. Molecular Therapy, Vol. 17, No. 7, (July), pp. 1145-1154, ISSN 1525-0016

Dong, J.Y., Fan, P.D., and Frizzell, R.A. (1996) Quantitative analysis of the packaging capacity of recombinant adeno-associated virus. Human Gene Therapy, Vol. 7, No. 17, (November), pp. 2101-2112, ISSN 1043-0342 
Dooriss, K.L., Denning, G., Gangadharan, B., Javazon, E.H., McCarty, D., Spencer, H.T., and Doering C.B. (2008) Comparison of factor VIII transgenes bioengineered for improved expression in gene therapy of hemophilia A. Human Gene Therapy, Vol. 20, No. 5, (May), pp. 465-478, ISSN 1043-0342

Dorner, A.J., Bole, D.G., and Kaufman, R.J. (1987) The relationship of N-linked glycosylation and heavy chain-binding protein association with the secretion of glycoproteins. Journal of Cell Biology, Vol. 105, No. 6, (December), pp. 2665-2674, ISSN 0021-9525

Essner, J.J., McIvor, R. S., and Hackett, P.B. (2005) Awakening gene therapy with Sleeping Beauty transposons. Current Opinion in Pharmacology, Vol. 5, No. 5, (October), pp.513-519, ISSN 1471- 4892

Gangadharan, B., Parker, E., Ide, L., Spencer, T., and Doering, C. (2006) High level expression of porcine FVIII from genetically modified bone marrow-derived stem cells. Blood, Vol. 107, No. 10, (May) pp. 3859-3864, ISSN 0006-4971

Grieger, J.C., and Samulski, R.J. (2005) Packaging capacity of adeno-associated virus serotypes: impact of larger genomes on infectivity and postentry steps. Journal of Virology, Vol. 79, No. 15, (August), pp. 9933-9944, ISSN 1098-5514

Hacein-Bey-Abina, S., von Kalle, C., Schmidt, M., Le Deist, F., Wulffraat, N., McIntyre, E., Radford, I., Villeval, J.L., Fraser, C.C., Cavazzana-Calvo, M., and Fischer, A. (2003) A serious adverse event after successful gene therapy for $\mathrm{X}$-linked severe combined immunodeficiency. New England Journal of Medicine, Vol. 348, No. 3, (January), pp. 255-256, ISSN 0028-4793

Hallek, M., Girod, A., Braun-Falco, M., Wendtner, C.M., Bogedain, C., and Hörer, M. (1998) Recombinant adeno-associated virus vectors. IDrugs, Vol. 1, No. 5, (September), pp. 561-573, ISSN 1369-7056

Hermonat, P.L., and Muzyczka, N. (1984) Use of adeno-associated virus as a mammalian DNA cloning vector: transduction of neomycin resistance into mammalian tissue cultured cells. Proceedings of the National Academy of Sciences, Vol. 81, No. 20, (October), pp. 6466-6470, ISSN 0027-8424

$\mathrm{Hu}$, C., Clea, R., Suzuki, M., Lee, B., and Lipshutz, G.S. (2011) Neonatal helper-dependent adenoviral vector gene therapy mediates correction of hemophilia A and tolerance to human factor VIII. Proceedings of the National Academy of Sciences, Vol. 108, No. 5, (Feruary), pp. 2082-2087, ISSN 0027-8424

Ide, L., Gangadharan, B., Chiang, K., Doering, C., and Spencer, T. (2007) Hematopoietic stem-cell gene therapy of hemophilia A incorporating a porcine FVIII transgene and nonmyeloablative conditioning regimens. Blood, Vol. 110, No. 8, (October), pp. 2855-2863, ISSN 0006-4971

Ivics, Z., Hackett, P.B., Plasterk, R.H., and Izsvak, Z. (1997) Molecular reconstruction of Sleeping Beauty, a Tc1-like transposon from fish, and its transposition in human cells. Cell, Vol. 91, No. 4, (November), pp. 501-510, ISSN 0092-8674

Jeon, H., Oh, T.K., Kim, O.H., and Kim, S.T. (2010) Delivery of Factor VIII gene into skeletal muscle cells using lentiviral vector. Yonsei Medical Journal, Vol. 51, No. 1, (January), pp. 52-57, 0513-5796

Jiang, H., Lillicrap, D., Patarroyo-White, S., Liu, T., Qian, X., Scallan, C.D., Powell, S., Keller, T., McMurray, M., Labelle, A., Nagy, D., Vargas, J.A., Zhou, S., Couto, L.B., and 
Pierce GF. (2006) Multiyear therapeutic benefit of AAV serotypes 2, 6, and 8 delivering factor VIII to hemophilia A mice and dogs. Blood, Vol. 108, No. 1, (July), pp. 107-115, ISSN 0006-4971

Johnston, J.M., Moot, R., Doering, C., and H. Trent Spencer. (2010) Generation of an optimized lentiviral vector encoding a high-expression fVIII transgene for gene therapy of hemophilia A. Proceedings of the 13th Annual American Society of Gene and Cell Therapy Meeting, ABST\#230, Washington D.C., May, 2010

Jurlander, B., Thim, L., Klausen, NK., Persson, E., Kjalke, M., Rexen, P., Jørgensen, T.B., Østergaard, P.B., Erhardtsen, E., and Bjørn, S.E. (2001) Recombinant activated factor VII (rFVIIa): characterization, manufacturing, and clinical development. Seminars in Thrombosis and Hemostasis, Vol. 27, No. 4, (August) pp. 373-384, ISSN 0094-6176

Kasuda, S., Kubo, A., Sakurai, Y., Irion, S., Ohashi, K., Tatsumi, K., Nakajima, Y., Saito, Y., Hatake, K., Pipe, S., Shima, M., and Yoshioka, A. (2008) Establishment of embryonic stem cells secreting human factor VIII for cell-based treatment of hemophilia A. Journal of Thrombosis and Haemostasis, Vol. 6, No. 8, (August), pp. 1352-1359, ISSN 1538-7933

Kingdon, H.S. and Hassell, T.M. (1981) Hemophilic dog model for evaluating therapeutic effectiveness of plasma protein fraction. Blood, Vol. 58, No. 5, (November), pp. 868872, ISSN 0006-4971

Klein, R., Ruttkowski, B., Knapp, E., Salmons, B., Gunzburg, W, and Hohenadl, C. (2006) WPRE-mediated enhancement of gene expression is promoter and cell line specific. Gene, Vol. 372, (May), pp. 153-161, ISSN 0378-1119

Kotin, R.M., Siniscalco, M., Samulski, R.J., Zhu, X.D., Hunter, L., Laughlin, C.A., McLaughlin, S., Muzyczka, N., Rocchi, M., and Berns, K.I. (1990) Site-specific integration by adeno-associated virus. Proceedings of the National Academy of Sciences, Vol. 87, No. 6, (March), pp. 2211-5, ISSN 0027-8424

Kren, B., Unger, G., Sjeklocha, L., Trossen, A., Korman, V., Diethelm-Okita, B., Reding, M., and Steer, C. (2009) Nanocapsule-delivered Sleeping Beauty mediates therapeutic Factor VIII expression in liver sinusoidal endothelial cells of hemophilia A mice. Journal of Clinical Investigation, Vol. 119, No. 7, (July), pp. 2086-2098, ISSN 00219738

Kumar, M., Keller, B., Makalou, N., and Sutton, R.E (2001) Systemic determination of the packaging limit of lentiviral vectors. Human Gene Therapy, Vol. 12, No. 15, (October), pp. 1893-905, ISSN 1043-0342

Laughlin, C.A., Tratschin, J.D., Coon, H., and Carter, B.J. (1983) Cloning of infectious adenoassociated virus genomes in bacterial plasmids. Gene. Vol. 23, No. 1, (July), pp. 6573, ISSN 0378-1119

Lenging, P.J., van Mourik, J.A., and Mertens, K. (1998) The life cycle of coagulation factor VIII in view of its structure and function. Blood, Vol. 92, No. 11, (December), pp. 3983-3996, ISSN 0006-4971

Liras, A. (2011) Induced human pluripotent stem cells and advanced therapies. Future perspectives for the treatment of haemophilia? Thrombosis Research, Vol. 10, (March), pp. 1-6, ISSN 0049-3848 
Liu, L., Mah, C., and Fletcher, B. (2006) Sustained FVIII expression and phenotypic correction of hemophilia A in neonatal mice using an endothelial-targeted Sleeping Beauty transposon. Molecular Therapy, Vol. 13, No. 5, (May), pp. 1006-1015, ISSN 1525-0016

Lu, H., Chen, L., Wang, J., Huack, B., Sarkar, R., Zhou, S., Xu, R., Ding, Q., Wang, X., Wang, H., and Xiao, W. (2008) Complete correction of hemophilia A with adeno-associated viral vectors containing a full-size expression cassette. Human Gene Therapy, Vol. 19, No. 6, (June), pp. 648-654, ISSN 1043-0342

Manno, C.S., Pierce, G.F., Arruda, V.R., Glader, B., Ragni, M., Rasko, J.J., Ozelo, M.C., Hoots, K., Blatt, P., Konkle, B., Dake, M., Kaye, R., Razavi, M., Zajko, A., Zehnder, J., Rustagi, P.K., Nakai, H., Chew, A., Leonard, D., Wright, J.F., Lessard, R.R., Sommer, J.M., Tigges, M., Sabatino, D., Luk, A., Jiang, H., Mingozzi, F., Couto, L., Ertl, H.C., High, K.A., and Kay, M.A. (2005) Successful transduction of liver in hemophilia by AAV-Factor IX and limitations imposed by the host immune response. Nature Medicine, Vol. 12, No. 3, (March), pp. 342-347, ISSN 1078-8956

Margaritis, P., Roy, E., Aljamali, M.N., Downey, H.D, Giger, U., Zhou, S., Merricks, E., Dillow, A., Ezban, M., Nichols, T.C., and High, K.A. (2009) Successful treatment of canine hemophilia by continuous expression of canine FVIIa. Blood, Vol. 113, No. 16, (April), pp. 3682-3689, ISSN 0006-4971

Margaritis, P., Roy, E., Faella, A., Downey, H.D., Ivanciu, L., Pavani, G., Zhou, S., Bunte, R.M., and High, K.A. (2011) Catalytic domain modification and viral gene delivery of activated Factor VII confers hemostasis at reduced expression levels and vector doses in vivo. Blood, Vol. 118, No. 4, (February), pp. 1-22, ISSN 0006-4971

Marquette, K.A., Pittman, D.D., and Kaufman, R.J. (1995) A 110-amino acid region within the A1-domain of coauglation factor VIII inhibits secretion from mammalian cells. Journal of Biological Chemistry, Vol. 270, No. 17, (April), pp. 10297-10303, ISSN 00219258

Matsui, H., Masaru, S., Brown, B., Labelle, A., Hegadorn, C., Andrews, C., Hebbel, R., Galipeau, J., Hough, C., and Lillicrap, D. (2007) Ex vivo gene therapy for hemophilia A that enhances safe delivery and sustained in vivo factor VIII expression from lentivirally engineered endothelial progenitors. Stem Cells, Vol. 25, No. 10, (October), pp. 2660-2669, ISSN 1066- 5099

Matsui, H., Hegadorn, C., Ozelo, M., Burnett, E., Tuttle, A., Labelle, A., McCRay, P.B., Naldini, L., Brown, B., Hough, C., and Lillicrap, D. (2011) A microRNA-regulated and GP64-pseudotyped lentiviral vector mediates stable expression of FVIII in a murine model of hemophilia A. Molecular Therapy, Vol 1., (February), pp. 1-8, ISSN 1525-0016

McIvor, R.S., Johnson, M.J., Miller, A.D., Pitts, S., Williams, S.R., Valerio, D., Martin, D.W., and Verma, I.M. (1987) Human purine nucleoside phosphorylase and adenosine deaminase: gene transfer into cultured cells and murine hematopoietic stem cells by using recombinant amphotropic retroviruses. Molecular and Cellular Biology, Vol. 7, No. 2, (February), pp. 838-846, ISSN 1098-5549

Meulien, P., Faure, T., Mischler, F., Harrer, H., Ulrich, P., Bouderbala, B., Dott, K., Sainte Marie, M., Mazurier, C., Wiesel, M.L., van de Pol, H., Cazenave, J.P., Courtney, M., 
and Pavirani, A. (1988) A new recombinant procoagulant protein derived from the cDNA encoding human factor VIII. Protein Engineering, Vol. 2, No. 4, (October), pp. 301-306, ISSN 0269-2139

Miao, H.Z., Sirachainan, N., Palmer, L., Kucab, P., Cunningham, M.A., Kaufman, R.J., and Pipe, S.W. (2004) Bioengineering of coagulation factor VIII for improved secretion. Blood, Vol. 103, No. 9, (May), pp. 3412-3419, ISSN 0006-4971

Muruve, D.A., Barnes, M.J., Stillman, I.E., and Libermann, T.A. (1999) Adenoviral gene therapy leads to rapid induction of multiple chemokines and acute neutrophildependent hepatic injury in vivo. Human Gene Therapy, Vol. 10, No. 6, (April), pp. 965-976, ISSN 1043-0342

Naldini, L., Blömer, U., Gallay, P., Ory, D., Mulligan, R., Gage, F.H., Verma, I.M., and Trono D. (1996) In vivo gene delivery and stable transduction of non-dividing cells by a lentiviral vector. Science, Vol. 272, No. 5259, (April), pp. 263-267, ISSN 0036-8075

Ohlfest, J.R., Frandsen, J.L., Fritz, S., Lobitz, P.D., Perkinson, S.G., Clark, K.J., Nelsestuen, G., Key, N.S., McIvor, R.S., Hacket, P.B., and Largaespada, D.A. (2005) Phenotypic correction and long-term expression of factor VIII in hemophilic mice by immunotolerization and nonviral gene transfer using the Sleeping Beauty transposon system. Blood, Vol. 105, No. 7, (April), pp. 2691-2698, ISSN 0006-4971

Ohmori, T., Ishiwata, A., Kashiwakura, Y., Madoiwa, S., Mitomo, K., Suzuki, H., Hasegawa, M., Mimuro, J., and Sakata, Y. (2008) Phenotypic correction of Hemophilia A by ectopic expression of activated factor VII in platelets. Molecular Therapy, Vol. 16, No.8, (August), pp. 1359-1365, ISSN 1525-0016

Porada, C.D., Sanada, C., Long, C.R., Wood, J.A., Desai, J., Frederick, N., Millsap, L., Bormann, C., Menges, S.L., Hanna, C., Flores-Foxworth, G., Shin, T., Westhusin, M.E., Liu, W., Glimp, H., Zanjani, E.D., Lozier, J.N., Pliska, V., Stranzinger, G., Joerg, H., Kraemer, D.C., and Almeida-Porada, G. (2010) Clinical and molecular characterization of a re-established line of sheep exhibiting hemophilia A. Journal of Thrombosis and Haemostasis, Vol. 8, No. 2, (Feruary), pp. 276-85, ISSN 1538-7933

Powell, J.S., Ragni, M.V., White, G.C., Lusher, J.h, Hillman-Wiseman, C., Cole, V., Jolly, D., Ramanathan-Girish, S., Roehl, H., Lu, B, and Hurst, D. (2003) Phase 1 trial of FVIII gene transfer for severe hemophilia A using a retroviral construct administered by peripheral intravenous infusion. Blood, Vol. 102, No. 6, (September), pp. 2038-45, ISSN 0006-4971

Quinonez, R. and Sutton, R. (2002) Lentiviral vectors for gene delivery into cells. DNA and Cell Biology, Vol. 21, No. 12, (December), pp. 937-951, ISSN 1044-5498

Radcliffe, P., Sion, C.J.M., Wilkes, E.J., Custard, E.J., Beard, G.L., Kingsman, S.M., and Mitrophanous, K.A. (2008) Analysis of factor VIII mediated suppression of lentiviral vector titres. Gene Therapy, Vol. 15, No. 4, (February), pp. 289-297, ISSN 0969-7128

Roth, D.A., Tawa, N.E., O'Brien, J.M., Treco, D.A., and Selden, R.F. (2001) Nonviral transfer of the gene encoding coagulation factor VIII in patients with severe hemophilia. New England Journal of Medicine, Vol. 344, No. 23, (June), pp. 1735-42, ISSN 00284793 
Sarkar, R., Xiao, W., and Kazazian, H.H. (2003) A single adeno-associated virus (AAV) murine factor VVIII. Journal of Thrombosis and Haemostasis, Vol. 1, No. 2, (February), pp. 220-226, ISSN 1538-7933

Sarkar, R., Tetreault, R., Gao, G., Wang, L., Bell, P., Chandler, R., Wilson, J.M., and Kazazian, H.H. Jr. (2004) Total correction of hemophilia A mice with canine FVIII using an AAV 8 serotype. Blood, Vol. 103, No. 4, (February), pp. 1253-1260, ISSN 0006-4971

Sarkar, R., Mucci, M., Addya, S., Tetreault, R., Bellinger, D., Nichols, T., and Kazazian, H. (2006) Long-term efficacy of adeno-associated virus serotypes 8 and 9 in hemophili A dogs and mice. Human Gene Therapy, Vol. 17, No. 4, (April), pp. 427-439, ISSN 1043-0342

Samulski, R.J., Berns, K.I., Tan, M., and Muzyczka, N. (1982) Cloning of adeno-associated virus into pBR322: rescue of intact virus from the recombinant plasmid in human cells. Proceedings of the National Academy of Sciences, Vol. 79, No. 6, (March), pp. 2077-2081, ISSN 0027-8424

Scallan, C.D., Liu, T., Parker, A.E., Patarroyo-White, S.L., Chen, H., Jiang, H., Vargas, J., Nagy, D., Powell, S.K., Wright, J.F., Sarkar, R., Kazazian, H.H., McClelland, A., and Couto, L.B. (2003) Phenotypic correction of a mouse model of hemophilia A using AAV2 vectors encoding the heavy and light chains of FVIII. Blood, Vol. 102, No. 12, (December), pp. 3919-3926, ISSN 0006-4971

Schauber, C.A., Tuerk, M.J., Pacheco, C.D., Escarpe, P.A., and Veres, G. (2004) Lentiviral vectors pseudotyped with baculovirus gp64 efficiently transduce mouse cells in vivo and show tropism restriction against hematopoietic cell types in vitro. Gene Therapy, Vol. 11, No., 3, (February), pp. 266-275, ISSN 0969-7128

Schnell, M.A., Zhang, Y., Tazelaar, J., Gao, G.P., Yu, Q.C., Qian, R., Chen, S.J., Varnavski, A.N., LeClair, C., Raper, S.E., and Wilson, J.M. (2001) Activation of innate immunity in nonhuman primates following intraportal administration of adenoviral vectors. Molecular Therapy, Vol. 5, No. 1, (May), pp. 708-22, ISSN 15250016

Schuettrumpf, J., Herzog, R.W., Schlachterman, A., Kaufhold, A., Stafford, D.W., and Arruda, V.R. (2005) Factor IX variants improve gene therapy efficacy for hemophilia B. Blood, Vol. 105, No. 6, (March), pp.2316-2323, ISSN 00064971

Sinn, P.L., Sauter, S.L., and McCray, P.B. (2005) Gene therapy progress and prospects: Development of improved lentiviral and retroviral vectors - design, biosafety, and production. Gene Therapy, Vol. 12, No. 14, (July), pp. 1089-1098, ISSN 09697128

Toole, J.J., Pittman, D.D., Orr, E.C., Murtha, P., Wasley, L., and Kaufman, R.J. (1986) A large region (approximately equal to $95 \mathrm{kDa}$ ) of human factor VIII is dispensable for in vitro procoagulant activity. Proceedings of the National Academy of Sciences, Vol. 83, No. 16, (August), pp. 5939-42, ISSN 0027-8424

Van Damme, A., Chuah, M., Collen, D., and VandenDriessche, T. (2004) Onco-retroviral and lentiviral vector-based gene therapy for hemophilia: Preclinical Studies. Seminars in Thrombosis and Hemostasis, Vol. 30, No. 2, (April), pp. 185-195, ISSN 0094-6176 
Van den Biggelaar, M., Bouwens, E., Kootstr,a N., Hebbel, R., Voorberg, J., and Mertens, K. (2009) Storage and regulated secretion of factor VIII in blood outgrowth endothelial cells. Haematologica, Vol. 94, No. 5, (May), pp. 670-678, ISSN 0390-6078

VandenDriessche, T., Vanslembrouck, V., Goovaerts, I., Zwinnen, H., Vanderhaeghen, M.L., Collen, D., and Chuah, M.K. (1999) Long-term expression of human coagulation factor VIII and correction of hemophilia A after in vivo retroviral gene transfer in factor VIII-deficient mice. Proceedings of the National Academy of Sciences, Vol. 96, No. 18, (August), pp. 10379-84, ISSN 0027-8424

VandenDriessche T, Vanslembrouck V, Goovaerts I, VandenDriessche, T., Collen, D., and Chuah, M.K. (2001) Viral vector-mediated gene therapy for hemophilia. Current Gene Therapy, Vol. 1, No. 3, (September), pp. 301-315, ISSN 1566-5232

Viiala, N., Larsen, S., and Rasko, J. (2009) Gene Therapy for Hemophilia: Clinical Trials and Technical Tribulations. Seminars in Thrombosis and Hemostasis, Vol. 35, No. 1, (February), pp. 81-92, ISSN 0094-6176

Ward, N.J., Buckley, S.M., Waddington, S.N., VandenDriessche, T., Chuah, M.K.L., Nathwani, A.C., McIntosh, J., Tuddenham, E.G.D., Kinnon, C., Thrasher, A.J., and McVey, J. (2011) Codon optimization of human factor VIII cDNAs leads to high-level expression. Blood, Vol. 117, No. 3, (January), pp. 798-807, ISSN 00064971

Wu, X., Li, Y., Crise, B., and Burgess, S.M. (2003) Transcription start regions in the human genome are favored targets for MLV integration. Science, Vol. 300, No. 5626, (June), pp. 1749-1751, ISSN 0036-8075

Wu, Z., Yang, H., and Colosi, P. (2010) Effect of genome size on AAV vector packaging. Molecular Therapy, Vol. 18, No. 1, (January), pp. 80-86, ISSN 1525-0016

Xu, D., Alipio, Z., Fink, L., Adcock, D., Yang, J., Ward, D., and Ma, Y. (2009) Phenotypic correction of murine hemophilia A using an iPS cell-based therapy. Proceedings of the National Academy of Sciences, Vol. 106, No. 3, (January), pp. 808-813, ISSN 00278424

Yacoub, N., Romanowska, M., Haritonova, N., and Foerster, J. (2007) Optimized production and concentration of lentiviral vectors containing large inserts. Journal of Gene Medicine, Vol. 9, No. 7, (July), pp. 579-584, ISSN 1521-2254

Yang, Y., Nunes, F.A., Berencsi, K., Furth, E.E., Gönczöl, E., and Wilson, J.M. (1994) Cellular immunity to viral antigens limits E1-deleted adenoviruses for gene therapy. Proceedings of the National Academy of Sciences, Vol. 91, No. 10, (May), pp. 4407-4411, ISSN 0027-8424

Yant, S., Meuse, L., Chiu, W., Ivics, Z., Isvak, Z., and Kay, M. (2000) Somatic integration and long-term transgene expression in normal and haemophilic mice using a DNA transposon system. Nature Genetics, Vol. 25, No. 1, (May) pp. 35-41, ISSN 10614036

Yonemura, H., Sugawara, K., Nakashima, K., Nakahara, Y., Hamamoto, T., Mimaki, I., Yokomizo, K., Tajima, Y., Masuda, K., Imaizumi, A., Funatsu, A., and Miyazaki, J. (1993) Efficient production of recombinant human factor VIII by co-expression of the heavy and light chains. Protein Engineering, Vol. 6, No. 6, (August), pp. 669-74, ISSN 0269-2139 
Youjin, S., and Jun, Y. (2009) The treatment of hemophilia A: from protein replacement to AAV-mediated gene therapy. Biotechnology Letters, Vol. 31, No. 3, (March), pp. 321328, ISSN 0141-5492

Zayed, H., Izsvák, Z., Walisko, O., and Ivics, Z. (2004) Development of hyperactive Sleeping Beauty transposon vectors by mutational analysis. Molecular Therapy, Vol. 9, No. 2, (February), pp. 292-304, ISSN 1525-0016

Zhu, J., Kren, B.T., Park, C.W., Bilgim, R., Wong, P.Y., and Steer, C.J. (2007) Erythroidspecific expression of beta-globin by the Sleeping Beauty transposon for Sickle cell disease. Biochemistry, Vol. 46, No. 23, (June), pp. 6844-58, ISSN 1507-1521

Zufferey, R., Donello, J.E., Trono, D., and Hope, T.J. (1999) Woodchuck hepatitis virus posttranscriptional regulatory element enhances expression of transgenes delivered by retroviral vectors. Journal of Virology, Vol. 73, No. 4, (April), pp. 2886-2892, ISSN 1098-5514 


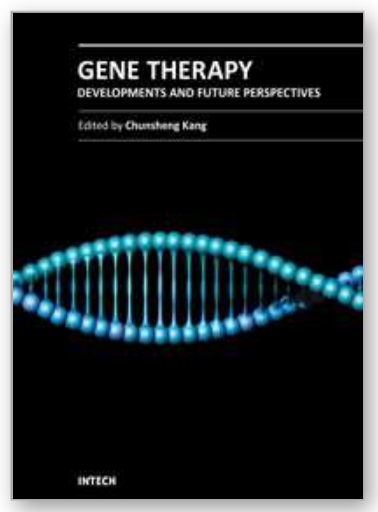

\author{
Gene Therapy - Developments and Future Perspectives \\ Edited by Prof. Chunsheng Kang
}

ISBN 978-953-307-617-1

Hard cover, 356 pages

Publisher InTech

Published online 22, June, 2011

Published in print edition June, 2011

The aim of this book is to cover key aspects of existing problems in the field of development and future perspectives in gene therapy. Contributions consist of basic and translational research, as well as clinical experiences, and they outline functional mechanisms, predictive approaches, patient-related studies and upcoming challenges in this stimulating but also controversial field of gene therapy research. This source will make our doctors become comfortable with the common problems of gene therapy and inspire others to delve a bit more deeply into a topic of interest.

\title{
How to reference
}

In order to correctly reference this scholarly work, feel free to copy and paste the following:

Jennifer Johnston, Christopher B. Doering and H. Trent Spencer (2011). Gene Therapy Strategies Incorporating Large Transgenes, Gene Therapy - Developments and Future Perspectives, Prof. Chunsheng Kang (Ed.), ISBN: 978-953-307-617-1, InTech, Available from: http://www.intechopen.com/books/genetherapy-developments-and-future-perspectives/gene-therapy-strategies-incorporating-large-transgenes

\section{INTECH}

open science | open minds

\section{InTech Europe}

University Campus STeP Ri

Slavka Krautzeka 83/A

51000 Rijeka, Croatia

Phone: +385 (51) 770447

Fax: +385 (51) 686166

www.intechopen.com

\section{InTech China}

Unit 405, Office Block, Hotel Equatorial Shanghai

No.65, Yan An Road (West), Shanghai, 200040, China

中国上海市延安西路65号上海国际贵都大饭店办公楼405单元

Phone: +86-21-62489820

Fax: $+86-21-62489821$ 
(C) 2011 The Author(s). Licensee IntechOpen. This chapter is distributed under the terms of the Creative Commons Attribution-NonCommercialShareAlike-3.0 License, which permits use, distribution and reproduction for non-commercial purposes, provided the original is properly cited and derivative works building on this content are distributed under the same license. 